\title{
Childhood and adolescent predictors of early and middle adulthood alcohol use and problem drinking: the Columbia County Longitudinal Study
}

\author{
Eric F. Dubow ${ }^{1,2}$, Paul Boxer ${ }^{1,3}$ \& L. Rowell Huesmann' \\ University of Michigan, USA,' Bowling Green State University, USA² and Rutgers University, Newark, USA ${ }^{3}$
}

\begin{abstract}
Aims To examine the role of individually and contextually based factors measured during childhood and adolescence in predicting alcohol use and abuse measured during early and middle adulthood. Design Initial sample of 856 individuals first interviewed at age 8 with follow-up interviews at $19(n=427), 30(n=409)$, and $48(n=523)$. Participants Individuals enrolled in 3rd-grade classes in Columbia County, NY, in 1960 (49\% female; > 90\% Caucasian; primarily working-class families), who were re-sampled in 1970 ( $51 \%$ female), 1981 ( $52 \%$ female) and 2000 (49\% female). Measurements Parent reports of negative family interaction and socio-economic status when the child was 8 years old; IQ test at age 8; peer nominations of aggression, popularity and behavioral inhibition at ages 8 and 19; self-report of depression and educational attainment at age 19; self-report of alcohol use and problem drinking at ages 30 and 48. Findings Path models showed that the effects of childhood individual variables (e.g. aggression, popularity, behavioral inhibition) on adulthood alcohol use and abuse generally were mediated by the same behavioral variables in adolescence. Specifically, both for males and for females, lower levels of behavioral inhibition and higher levels of aggression predicted adulthood alcohol variables. Childhood contextual variables (family socio-economic status and negative family interaction) were relatively weak predictors of adulthood alcohol use and abuse. Conclusions Alcohol use and abuse in adulthood, when considered in a long-term developmental-contextual framework, appear to be consistent with a general deviance model of problem behavior whereby individually based factors from childhood and late adolescence predict long-term indices of adulthood alcohol use and abuse.
\end{abstract}

Keywords Adolescence, adulthood, alcohol, childhood, problem behavior.

Correspondence to: Eric F. Dubow, University of Michigan, Institute for Social Research, 426 Thompson Street, Ann Arbor, MI 48106-1248, USA.

E-mail: edubow@bgnet.bgsu.edu

Submitted 17 October 2007; initial review completed 3 December 2007; final version accepted 28 January 2008

\section{INTRODUCTION}

The development and persistence of problem drinking patterns and alcohol use disorders (e.g. alcohol dependence) have been studied from a variety of sociopsychological, biomedical and genetic perspectives [1]. Problem drinking is a multiply determined behavior: individuals who tend towards problem drinking are predisposed to do so on account of, among other factors, behavioral disinhibition, negative affectivity and, to some extent, antisociality. The consumption of alcohol also requires access to alcohol and, at least in the early stages of habitual problem drinking, appropriate contextual support (e.g. peer use). However, problem drinking during adulthood generally is predictable from factors measurable during childhood (e.g. aggression, family conflict) [2]. Yet the considerable social, neurological and contextual changes that occur during adolescence might affect this relation. As Schulenberg et al. [3] have reported, there is significant interindividual variation in problem drinking patterns during the transition to adulthood period (i.e. about 18-25 years of age). For example, whereas about $24 \%$ of this population does not engage in any problem drinking, about $12 \%$ are chronic problem drinkers, $13 \%$ begin the period at high levels only to decline by about age 24 and about $9 \%$ have a 'fling' with problem drinking between the ages of 19 and 22 [3]. 
To date, there still is relatively little research assessing the independent and additive impact of childhood and adolescent factors on drinking patterns into middle adulthood. In this paper, we rely on data from the 40-year Columbia County Longitudinal Study [4] to examine the prediction of alcohol use and abuse in early and middle adulthood from risk factors measured in middle childhood (age 8) and late adolescence (age 19). Our prospective design permits us to consider the impact of functioning at those two developmental periods on drinking (general quantity/frequency; problem drinking) during early (age 30) and middle (age 48) adulthood.

\section{Problem drinking as a problem behavior: general deviance and social-contextual models}

As Zucker [1] and others [5] have observed, alcohol misuse can be conceptualized as a problem behavior, akin to delinquency, use and abuse of other substances and sexual promiscuity. Because of this, the multi-level risk matrix shown to account for the emergence and maintenance of problem behavior more generally can also be applied to understanding how individuals might come to engage in problem drinking. A variety of developmental models of problem behavior have been proposed. For example, research in the Problem Behavior Theory and general deviance syndrome models [6] highlights an individual's propensity to behave in a deviant, antisocial manner as the key factor accounting for the expression of such behavior. This propensity might be comprised of an assortment of motivations, beliefs and perceptions of control [7], a pervasive lack of self-control over impulsive responding [8] or neurophysiological deficits [9]. The general deviance syndrome view acknowledges the importance of contextual influences in the expression of problem behaviors; innate tendencies toward problem behavior are brought out through interactions with certain contextual influences such as antisocial peer group affiliations. However, the central idea in the general deviance framework is that problem behaviors are the manifestation of stable individual predispositions.

Studies assuming a more social-contextual view on the development of problem behavior have pointed to the importance of various ecological influences. Here, in addition to individual predispositions to behave in certain ways, responses are shaped primarily through parental modeling [10], neighborhood characteristics and events [11] and exposure to media representations of behavior [12]. In this view, although some predisposition towards problematic behavior is necessary (e.g. trait impulsivity or irritability), social learning is required for problem behavior to take hold. In the social-developmentalpsychological research tradition, more support has been observed for a social-contextual view in comparison to a general deviance view on the development of problem behavior [13]. As noted, with respect to alcohol abuse in particular, it is also essential to consider intergenerational, genetic and neurobiological sources of risk, and the more compelling 'take-home message' of research on problem behavior generally is that such behavior is multiply determined. The focus of the current investigation is on factors that contribute to the emergence and persistence of problem drinking in adulthood.

\section{A developmental perspective}

Alcohol misuse is one form of problem behavior [5] that has received substantial attention with respect to studying developmental persistence. However, research on developmental aspects of alcohol use has been hampered by the fairly limited time-periods used to evaluate this issue. Only a handful of long-term studies predict alcohol use during early adulthood from variables measured in childhood (e.g. problems of undercontrol such as hyperactivity and high novelty seeking; internalizing problems such as shyness and high harm avoidance) [1]. Further, because individuals do not commonly initiate alcohol use until early adolescence [2,14], childhood indicators of this particular form of problem behavior are not available. A number of studies have considered the links between adolescent alcohol use and young adult alcohol use and abuse. For example, Schulenberg and colleagues [15] and Chassin and colleagues [16] have shown that some individuals show consistently high levels of problem drinking from adolescence to early adulthood, whereas others show hardly any or instead exhibit increases or decreases during that period $[17,18]$.

As indicators of problem behavior, alcohol use and abuse are particularly interesting for a variety of reasons. First, alcohol use is fairly common throughout late adolescence and well into adulthood. For example, US trends observed over the past 15 years in the Monitoring the Future study suggest a 30-day point prevalence of alcohol use of about 17-25\% among 8th-graders, $33-43 \%$ among 10 th-graders and $47-54 \%$ among 12 thgraders [19]. By about age 25, 30-day prevalence rates appear to stabilize at about $60-70 \%$ of the population [20]. Thus, in contrast to other forms of substance use as well as other problem behaviors, alcohol use is quite normative. Secondly, in most states, for adolescents below the age of 21 , alcohol is illegal and thus is a problem regardless of the quantity in which it is consumed. For individuals aged 21 and older, alcohol is legal and thus becomes a problem only on account of the quantities in which it is consumed. Therefore, the factors that predict drinking and other types of problem behavior in adolescence might be different from those that predict alcohol use in adulthood, but perhaps similar to those that predict 
alcohol abuse in adulthood. Finally, because alcohol use can represent both normative (i.e. casual use) and nonnormative (i.e. alcohol use disorders) behaviors, it might not conform to the typical developmental model of problem behavior.

\section{The current study}

The purpose of the current study was to examine the prediction of alcohol use and problem drinking during early (age 30) and middle (age 48) adulthood as a function of social and behavioral factors measured during middle childhood (age 8) and late adolescence (age 19). We examine alcohol use via the frequency and quantity of consumption, and problem drinking via an assessment of the negative social and legal consequences of consumption. As noted, previous research has examined childhood predictors of alcohol use in adulthood. Our 40-year data permit a longer-term life-span approach to predicting alcohol use in adulthood. Given the importance of adolescence in determining adult drinking patterns, we hypothesized that alcohol use during both adulthood time-points would be accounted for significantly by adolescent functioning. However, in line with studies on the development of problem behavior more generally, and research illuminating the enduring effects of middle childhood behavior and context [21], we also hypothesized that adult outcomes would be in part determined by variables measured in childhood. Also consistent with the behavioral continuity observed typically in longitudinal studies of problem behavior [4], we hypothesized a link between childhood predictors and adult outcomes mediated in part by adolescent factors.

\section{METHOD}

\section{Design of the Columbia County Longitudinal Study}

The Columbia County Longitudinal Study (CCLS [22-25]) began in 1960 and has resulted so far in the collection of four waves of data over a 40-year span on children who were living in Columbia County, NY, in 1960. The entire population of 3rd-graders $(n=856$; 436 boys, 420 girls) in the county participated in the project's first wave in 1960 [22], when $85 \%$ of participants' mothers and $71 \%$ of their fathers also were interviewed. Follow-up assessments were conducted in 1970 $(n=427), 1981(n=409)$, and recently in 1999-2002 $(n=523)[4]$.

\section{Description of CCLS sample}

Columbia County, NY, is semi-rural with a few heavy industries. Of its approximately 63000 current residents, about 7500 live in the largest city and county seat,
Hudson. The county has had a depressed economy for the last 50 years, although it has begun to benefit from the encroachment of the New York City metropolitan area. At the time the study began, there were 38 public and private 3rd-grade classrooms in the county, all of which were included in the sample. Over $90 \%$ of the original sample of 856 participants was Caucasian; 51\% were male and $49 \%$ were female. The number of ethnic minorities (i.e. 3\% African American, < 1\% Asian or Pacific Islanders, $<1 \%$ Hispanic) was too small to allow separate analyses. The participants came from a broad range of socio-economic backgrounds [mean $=5.01$, standard deviation $(\mathrm{SD})=2.23$ on a 10-point scale of father's occupational status derived by Eron and colleagues [22], based on a previously developed seven-point scale [26]; this mean reflects jobs such as craftsmen, foremen and skilled tradesmen] and displayed a wide range of intelligence (mean IQ 104, SD=14). The 427 participants (211 boys, 216 girls) who were re-interviewed in 1970 had a modal age of 19 years and had completed 12.6 years of education on average. In 1981,409 of the original participants were reinterviewed (modal age 30; 198 males, 211 females). The average educational level of the sample was 'some college or technical school', and the mean verbal achievement, as indicated by an average of the spelling and reading scores on the Wide Range Achievement Test (WRAT) [27], was $96.34(\mathrm{SD}=19.22)$, reflecting fairly average achievement.

For the 523 participants (268 males, 255 females, $61 \%$ of the original sample) re-interviewed during 1999 2002 , mean age was 48.46 years old $(S D=0.77)$; the average education level was between some college and a college degree; the average occupational attainment was middle-class status (the average occupational prestige code using Stevens \& Hoisington's [28] scores reflected jobs such as sales, book-keepers, secretaries); and 69\% were living with spouses. The mean verbal achievement score on the WRAT was $99.15(\mathrm{SD}=13.72)$.

\section{Examination of attrition}

In the 40-year follow-up, we interviewed $523(61 \%)$ of the original sample of 856 . Of the non-interviewed participants, $37(4 \%)$ had died, $112(13 \%)$ could not be found despite intense efforts, 40 (5\%) could not be interviewed because of distance and scheduling difficulties and $144(17 \%)$ refused. The completed re-interview rate of $61 \%$ over 40 years still provides us with a sizeable sample for analysis. A comparison of means on age 8 scores revealed that compared to participants who were re-interviewed in wave 4 , participants who were not re-interviewed had higher levels of aggression, $t_{854}=3.98, P<0.001$ and lower levels of popularity, 
$t_{854}=4.23, P<0.001$, behavioral inhibition, $t_{854}=3.86$, $P<0.001$ and $\mathrm{IQ}, t_{852}=5.72, P<0.001$. However, the plots of the distributions for these age 8 variables revealed that many of the high aggressive and low competent participants were re-sampled and there was no substantial restriction of range that might have made it difficult to detect relations between these age 8 variables and adult outcomes. Participants who were not re-interviewed also had lower childhood socio-economic status (SES) than participants who were re-interviewed at age 48 , $t_{532}=3.15, P<0.001$, but there was no significant difference in age 8 negative family interactions. In terms of age 19 variables, participants who were not re-interviewed at wave 4 had lower levels of educational attainment, $t_{425}=4.06, \quad P<0.001$ and popularity, $t_{425}=2.86$, $P<0.01$. Attrition was not related to age 19 aggression, behavioral inhibition or depression.

Participants assessed at age 30 but not 48 and those assessed at both adult time-points did not differ on age 30 alcohol variables. Participants who were not assessed at age 30 but were re-assessed at age 48 did not differ on age 48 alcohol variables from participants who were available at both adulthood assessments. Thus attrition or re-entry into the study between adult time-points (ages 30 and 48) was not associated with scores on the alcohol use variables.

\section{Procedures}

Data collection methods for the first three waves of the CCLS have been reported elsewhere [22-24]. In wave 1 in 1960, two main sources of data were utilized: classroombased peer-nominations and extensive individual parent interviews. In wave 2 in 1970, participants were administered a variety of self-report measures as well as peer nominations, in individual interviews, at a field office. In both waves 3 (1981) and 4 (1999-2002), interviews were conducted by computer in a field office and by mail/ telephone for those participants who could not come to the office. In wave 3, participants were paid $\$ 50$ for their participation; in wave 4 , they were paid $\$ 100$ for their participation. Interviews ranged from 2 to 4 hours.

\section{Measures}

Family contextual variables

We examined two domains of family contextual factors, both measured at age 8 only: family SES and negative family interaction. For these variables, if two parents were interviewed, their scores were averaged.

Family SES variables-composite. (i) For father's occupational level, we used an occupational coding scale [26] adapted by Eron et al. [22]. Occupations were coded on a 10-point scale $(0=$ laborers to $9=$ professionals $)$; (ii) parents' educational level [22] reflects the parents' levels of educational attainment, ranging from $1=$ under 7 years to 7 = graduate/professional training; (iii) value of family housing [22] ranges from $1=$ inexpensive rental to $4=$ expensive owned. The composite score was derived through latent variable measurement modeling. Individual scores were standardized, multiplied by factor weights observed in the measurement model and summed to create the family background composite [4].

Negative family interaction-composite. Negative family interaction [22] was measured by three indicators: (i) Parental rejection is the sum of scores on 10 items about how 'unsatisfied' the parent is with the child, e.g. 'Are you satisfied with your child's manners? Does your child read as well as he/she should?' (yes/no) ( $\alpha=0.75)$; (ii) parents' endorsement of hitting the child as a form of punishment was the sum of parents' endorsement of physical punishment in response to two vignettes depicting child transgressions, e.g. 'If your child were rude to you, would you .... Two physical punishments were included: 'spank your child until he/she cries?' and 'slap your child in the face?' (yes/no); (iii) parental disharmony measures the amount and seriousness of disputes between the parents. It is the sum of 10 items of the form, 'Do you or your spouse ever leave the house during an argument?' and 'Do arguments between you and your spouse ever settle anything?' (yes/no) $(\alpha=0.77)$. The composite score was derived through latent variable measurement modeling. Individual scores were standardized, multiplied by factor weights observed in the measurement model and then summed to create the negative family interaction composite [4].

Ages 8 and 19 individual/personal variables. (1) Aggression. Eron et al. [22] defined aggression as 'an act whose goal response is injury to another object' (p. 30). Their 10 peer-nominated aggression items cover physical (e.g. 'Who pushes and shoves other children?'), verbal (e.g. 'Who says mean things?'), acquisitive (e.g. 'Who takes other children's things without asking?') and indirect (e.g. 'Who makes up stories and lies to get other children into trouble?') acts. The score represents the proportion of times the child was nominated by classmates on the 10 items (participants could nominate peers of either sex); thus, a child's score was equal to the total number of nominations received on the 10 items divided by the number of classmates. This measure is described in detail elsewhere [22-25] and has been used widely, with $\alpha \geq 0.90$ in cross-national samples, in the CCLS and in other US samples [29].

At age 19, because participants had left high school, interviews were conducted in the field office. Partici- 
pants first were presented with a list of those original participants who had attended school with them at age 8 , and were asked to identify those whom they knew currently 'well enough to answer some questions about.' Aggression was measured using the same peernominated items as at age 8 , save for the omission of one item ('Who says, "Give me that!"?'). Participants checked all the names that applied from the list of participants who fit each item. Each individual's score was computed as the number of times he/she was nominated on the nine questions divided by the number of times he or she could have been nominated (i.e. the number of participants who now knew the individual well). This measure was highly reliable $(\alpha=0.90$ across nine items). A square-root transformation was applied to reduce skewness and kurtosis.

(2) Popularity. This score represents the proportion of times the participant was nominated by his or her classmates on two popularity items, e.g. 'Who would you like to have as a best friend?' $(\alpha=0.87)$; popularity scores correlate negatively with aggression [22]. Popularity was assessed in this manner at ages 8 and 19.

(3) Behavioral inhibition. Eron et al.'s [22] 'anxiety over aggression' measure was used to assess behavioral inhibition. At ages 8 and 19, two peer-rated items measured this construct: "Who says "excuse me" even when they have done nothing wrong?' and 'Who will never fight even when picked on?'. Scores are computed similarly to the peer-nominated aggression measure. The internal consistency is 0.67. A square-root transformation was applied to reduce skewness and kurtosis. With respect to the overall age 19 peer nomination procedure, we note that despite the unique contingencies of this procedure, all the age 19 peer nomination measures described here have yielded good reliability and validity (i.e. significantly related to age 8 analogs; significantly predictive of age 30 and age 48 outcomes) [25].

(4) IQ/educational attainment. At age 8, the child's IQ was assessed with the California Short-Form Test of Mental Maturity [30]. Kuder-Richardson reliability coefficients range from 0.87 to 0.89 across grades; the total score correlates approximately 0.75 with other IQ measures. At age 19, IQ scores were not available. Instead, we used the participant's educational attainment $(1=\mathrm{did}$ not complete high school, 2 = high school degree only, $3=$ attending college).

(5) Depression. Depression was assessed at age 19 only, using the Minnesota Multiphasic Personality Inventory (MMPI) Scale 2 (depression) [31]. Greene [32] described the 60 items on scale 2 as assessing 'poor morale, lack of hope in the future, and general dissatisfaction' (p. 72). Test-re-test reliabilities of 0.8 to 0.9 (over periods up to one month) and 0.4 to 0.5 (over periods up to a year or more) have been reported [33].
Ages 30 and 48 alcohol use and alcohol problems. At age 30, participants reported their frequency of drinking in the past year along a seven-point scale $(1=$ never, $4=$ two to four times a month, 7 = approximately every day), as well as the number of drinks they had typically in one sitting. The score for frequency was converted into approximate number of days the participant drank during the year (e.g. two to four times a month was scored as 36 to reflect an average of three times a month $\times 12$ months; approximately every day was scored as 300 days per year). The quantity of use score is the product of this frequency score and number of drinks per sitting, which can be viewed as total number of drinks per year (e.g. two to four times a month $=36$ times per year, multiplied by two drinks per sitting, for a score of 72). At age 48, participants were asked whether they had used alcoholic beverages in the past year, and if so to indicate how often they drank alcohol in the past month $(0=$ not at all in past year, $1=$ in the past year but not in the past month, $2=$ one to two times in the past month to $7=40+$ times in the past month). Log transformations were applied to these scores to reduce skewness and kurtosis.

(2) Problem drinking. At age 30, a seven-item scale was used to assess the participant's self report of problem drinking. Sample items included, 'I have been arrested or involved in an accident as a result of drinking' and 'When drinking, I have become aggressive towards people or destroyed property'. Participants responded to these items on a four-point scale $(0=$ has never happened to me, 1 = has happened once, 2 = happens sometimes, 3 = happens frequently). The total score is the average of the responses to the items. If a participant indicated no drinking in the past year, a score of zero was assigned for problem drinking. An abbreviated four-item version of this scale (three of the same items and one additional item) was administered at age 48 (see Table 1 for all items at both ages). Internal consistency reliabilities for these scales have been found to be above 0.63. Log transformations were applied to these scores to reduce skewness and kurtosis. Table 1 summarizes the constructs assessed and measures indicating those constructs to facilitate comparison with the other papers in this special issue.

\section{RESULTS}

\section{Overview}

First, we report gender differences in all study variables. Next, we report correlations by gender of the ages 8 and 19 predictor variables with quantity of alcohol use and problem drinking in early adulthood (age 30). Then, we report the correlations by gender of the ages 8 and 19 predictor variables with frequency of alcohol use and problem drinking in middle adulthood (age 48). This 
Table 1 Constructs assessed and specific measures obtained by age.

\begin{tabular}{|c|c|c|}
\hline Age & Construct & Measure/description \\
\hline 8 & $\begin{array}{l}\text { Family socio-economic status } \\
\quad \text { (SES) }\end{array}$ & $\begin{array}{l}\text { Composite score summary of: (1) father's occupational prestige level; (2) parents' } \\
\text { educational level; (3) Value of family housing }\end{array}$ \\
\hline 8 & Negative family interaction & $\begin{array}{l}\text { Composite score summary of: (1) parental rejection of child (e.g. dissatisfaction with } \\
\text { child's manners and school performance); (2) parental endorsement of hitting } \\
\text { (slapping, spanking) child as a form of punishment; (3) parental disharmony } \\
\text { (amount and seriousness of interparental disputes) }\end{array}$ \\
\hline $8 / 19$ & Aggression & Peer-nominated aggressive behavior (e.g. pushing, shoving, saying mean things) \\
\hline $8 / 19$ & Popularity & Peer-nominated popularity (e.g. others want to have individual as best friend) \\
\hline $8 / 19$ & Behavioral inhibition & Peer-nominated anxiety over behaving aggressively (e.g. never fights when picked on) \\
\hline $8 / 19$ & $\mathrm{IQ} /$ educational attainment & $\begin{array}{l}\text { Age 8: IQ via California Short-Form Test of Mental Maturity } \\
\text { Age 19: Educational attainment trichotomized as never finished high school, finished } \\
\text { HS but not in college, finished HS and currently in college }\end{array}$ \\
\hline 19 & Depression & $\begin{array}{l}\text { Minnesota Multiphasic Personality Inventory (MMPI)—scale } 2 \text { (e.g. poor morale, lack } \\
\text { of hope in the future) }\end{array}$ \\
\hline $30 / 48$ & $\begin{array}{l}\text { Quantity/frequency of } \\
\text { alcohol use }\end{array}$ & $\begin{array}{l}\text { Age } 30 \text { quantity of alcohol use during the past year } \\
\text { Age } 48 \text { frequency of use alcohol use in the past year }\end{array}$ \\
\hline $30 / 48$ & Problem drinking & $\begin{array}{l}\text { Items assessing frequency of experiencing negative consequences of alcohol use: } \\
\text { 1. Alcohol use has caused me to lose close friends or damaged relationships } \\
\text { 2. Alcohol use led me to miss an appointment or lose a job } \\
\text { 3. I have awakened the next day not being able to remember some of the things I had } \\
\text { done while drinking } \\
\text { 4. A family member has complained about the amount of money spent on drinking. } \\
\text { 5. After starting to drink it is difficult to stop before becoming intoxicated } \\
\text { 6. I have been arrested or involved in an accident as a result of drinking } \\
\text { 7. When drinking, I have become aggressive towards people or destroyed property } \\
\text { 8. Sometimes I have been concerned that the amount I drink might cause me } \\
\text { problems in the future } \\
\text { Age } 30 \text {, items } 1-7 \text {; age } 48 \text {, items } 5-8\end{array}$ \\
\hline
\end{tabular}

examination of mean differences and correlations by gender provides descriptive information to permit comparison with other data sets. Finally, using full information maximum likelihood estimation to deal with missing data, we calculate a path model that examines mediation effects of the adolescent and age 30 variables in the longitudinal relations between the age 8 variables and the middle adulthood (age 48) alcohol use and problem drinking variables.

\section{Gender differences}

At age 8, parents reported higher levels of negative family interactions in families in which boys were the original participants, $t_{699}=2.95, P<0.01$. Peers reported that boys had higher levels of aggression at age $8, t_{854}=5.62$, $P<0.01$ and age $19, t_{424}=6.39, P<0.01$ and higher levels of depression at age $19, t_{424}=3.80, P<0.01$; but girls had higher levels of behavioral inhibition at age 8 , $t_{854}=5.09, P<0.01$. There were no gender differences in family SES at age 8 , age 8 IQ or age 19 educational attainment.
In terms of the alcohol variables, by age 30 males reported a higher quantity of alcohol use, $t_{424}=7.50$, $P<0.01$, and problem drinking, $t_{389}=8.63, P<0.01$. Similarly, by age 48 , males reported a higher frequency of alcohol use, $t_{479}=2.17, P<0.05$, and problem drinking, $t_{481}=4.80, P<0.01$. Table 2 shows descriptive data for quantity/frequency of alcohol use and problem drinking reported by female and male participants at ages 30 and 48. Tables 3 and 4 display correlations among the ages 8 and 19 predictors and the ages 30 and 48 outcomes.

\section{A mediation model of the effects of the adolescent variables and early adulthood alcohol use in the relation between the age 8 variables and middle adulthood alcohol use}

To examine the possible mediational role of the adolescent variables and early adulthood alcohol use in the relation between the child variables and middle adulthood alcohol use, a series of two-group (females, males) path models were estimated using full information maximum likelihood estimation (FIML) in AMOS 4.01 [34]. FIML 
Table 2 Mean, median, and upper 10\% scores for females and for males on age 30 and age 48 frequency/quantity of alcohol use and problem drinking.

\begin{tabular}{|c|c|c|c|c|}
\hline & \multicolumn{2}{|l|}{ Age 30} & \multicolumn{2}{|l|}{ Age 48} \\
\hline & $\begin{array}{l}\text { Quantity (no. } \\
\text { of drinks in past year) }\end{array}$ & Problem drinking & Frequency & Problem drinking \\
\hline \multicolumn{5}{|l|}{ Mean (SD) } \\
\hline \multirow[t]{2}{*}{ Females } & $158.56(472.31)$ & $0.18(0.30)$ & $2.53(1.99)$ & $0.26(0.39)$ \\
\hline & $\begin{array}{l}1 \text { time/week, } 3 \text { drinks per } \\
\text { sitting; } 2-4 \text { times/week, } 1 \\
\text { drink per sitting }\end{array}$ & $\begin{array}{l}\text { Experienced a problem only } \\
\text { once on } 1 \text { of } 7 \text { items }\end{array}$ & Approx. 4 times/month & $\begin{array}{l}\text { Experienced a problem only } \\
\text { once on } 1 \text { of } 4 \text { items }\end{array}$ \\
\hline \multirow[t]{2}{*}{ Males } & $529.51(811.93)$ & $0.52(0.49)$ & $3.01(2.13)$ & $0.46(0.52)$ \\
\hline & $\begin{array}{l}\text { 2-4 times/week, 3-4 drinks } \\
\text { per sitting }\end{array}$ & $\begin{array}{l}\text { Experienced a problem only } \\
\text { once on 3-4 of } 7 \text { items; } \\
\text { experienced a problem on } \\
2 \text { items 'sometimes' }\end{array}$ & 6 times/month & $\begin{array}{l}\text { Experienced a problem only } \\
\text { once on } 2 \text { of } 4 \text { items; or } \\
\text { experienced } 1 \text { problem } \\
\text { 'sometimes' }\end{array}$ \\
\hline \multicolumn{5}{|l|}{ Median } \\
\hline \multirow[t]{2}{*}{ Females } & 48.00 & 0.00 & 2.00 & 0.00 \\
\hline & $\begin{array}{l}\text { 2-4 times/month, } 1 \text { drink } \\
\text { per sitting; one a month, } \\
4 \text { drinks per sitting }\end{array}$ & $\begin{array}{l}\text { Never experienced a } \\
\text { problem }\end{array}$ & 3 times/month & $\begin{array}{l}\text { Never experienced a } \\
\text { problem }\end{array}$ \\
\hline \multirow[t]{2}{*}{ Males } & 300.00 & 0.43 & 3.00 & 0.25 \\
\hline & $\begin{array}{l}\text { 2-4 times/week, 1-2 drinks } \\
\text { per sitting; approx. once a } \\
\text { week, } 5 \text { drinks per sitting }\end{array}$ & $\begin{array}{l}\text { Experienced a problem only } \\
\text { once on } 3 \text { of } 7 \text { items; } \\
\text { experienced a problem on } \\
1 \text { item 'frequently' }\end{array}$ & 6 times/month & $\begin{array}{l}\text { Experienced a problem only } \\
\text { once on } 1 \text { of } 4 \text { items }\end{array}$ \\
\hline \multicolumn{5}{|l|}{ Upper $10 \%$} \\
\hline \multirow[t]{2}{*}{ Females } & 387.00 & 0.57 & 5.00 & 0.75 \\
\hline & $\begin{array}{l}\text { 2-4 times/week, } 2 \text { drinks } \\
\text { per sitting; approx. every } \\
\text { day, } 1 \text { drink per sitting }\end{array}$ & $\begin{array}{l}\text { Experienced a problem only } \\
\text { once on } 4 \text { of } 7 \text { items; } \\
\text { experienced a problem on } \\
2 \text { items 'sometimes' }\end{array}$ & 3-4 days/week & $\begin{array}{l}\text { Experienced a problem only } \\
\text { once on } 3 \text { of } 4 \text { items; } \\
\text { experienced } 1 \text { problem } \\
\text { once and another } \\
\text { problem 'sometimes' }\end{array}$ \\
\hline \multirow[t]{2}{*}{ Males } & 1500.00 & 1.29 & 6.00 & 1.25 \\
\hline & $\begin{array}{l}\text { Approx. every day, } 5 \text { drinks; } \\
\text { 2-4 times/week, } 10 \\
\text { drinks per sitting }\end{array}$ & $\begin{array}{l}\text { Experienced a problem on } 6 \\
\text { items once and } 1 \text { item } \\
\text { 'frequently'; experienced } \\
\text { a problem on } 3 \text { items } \\
\text { 'frequently' }\end{array}$ & Approx. every day & $\begin{array}{l}\text { Experienced a problem once } \\
\text { on } 3 \text { items and } \\
\text { 'sometimes' on } 1 \text { item; } \\
\text { experienced one problem } \\
\text { 'sometimes' and another } \\
\text { problem 'frequently' }\end{array}$ \\
\hline
\end{tabular}

$\mathrm{SD}=$ standard deviation. Examples are provided to illustrate different ways a participant could have achieved a given score on the alcohol use variables.

assumes that missing data are "missing at random (MAR)' but not necessarily 'missing completely at random (MCAR)' [35]. Data are called 'missing at random' when whether an observation on a variable that is missing is correlated with other observed variables measured at the same or other times but is probably not correlated with other unmeasured constructs. As noted earlier, study attrition, and thus missingness on adult alcohol variables, were in fact related to several ages 8 and 19 individual and contextual predictors (e.g. aggression, IQ), but is unlikely to be related to other variables independently of those markers. Parameter estimates based on FIML estimation methods will be unbiased to the extent that variables related to missingness can be included within the estimated analytical models [36]; so these significant predictors of missingness were included.

In each model, the six independent variables from age 8 were allowed to covary with each other. Additionally, the residuals associated with the variables within each subsequent time-point (i.e. age 19, age 30 and age 48) were also allowed to covary with each other but not with any of the other residuals associated with variables across time points. Both quantity/frequency of alcohol use and problem drinking were included at age 30 and age 48 (the residuals associated with the two alcohol variables within each time point were allowed to covary with each other). 
Table 3 Correlations of age 8 and age 19 predictor variables with age 30 quantity of alcohol use and problem drinking.

\begin{tabular}{|c|c|c|c|c|}
\hline \multirow[b]{2}{*}{ Predictor variables } & \multicolumn{2}{|c|}{ Age 30 quantity of alcohol use } & \multicolumn{2}{|c|}{ Age 30 problem drinking } \\
\hline & Females & Males & Females & Males \\
\hline \multicolumn{5}{|l|}{ Age 8} \\
\hline Negative family interaction & -0.05 & 0.13 & 0.09 & 0.08 \\
\hline SES & 0.10 & 0.07 & $-0.15 \dagger$ & -0.11 \\
\hline Behavioral inhibition & 0.04 & $-0.14 \dagger$ & -0.11 & $-0.16^{*}$ \\
\hline Popularity & 0.08 & 0.03 & -0.09 & -0.06 \\
\hline $\mathrm{IQ}$ & 0.01 & -0.10 & 0.03 & -0.05 \\
\hline Aggression & -0.07 & $0.18^{*}$ & -0.06 & $0.16^{*}$ \\
\hline \multicolumn{5}{|l|}{ Age 19} \\
\hline Depression & 0.06 & 0.08 & -0.02 & $0.15 t$ \\
\hline Behavioral inhibition & $-0.19^{*}$ & $-0.20^{*}$ & $-0.28^{*}$ & $-0.33^{* *}$ \\
\hline Popularity & $0.14 \dagger$ & 0.10 & -0.11 & 0.00 \\
\hline Educational attainment & 0.04 & -0.13 & 0.01 & $-0.15 \dagger$ \\
\hline Aggression & $0.27^{* *}$ & $0.23^{*}$ & $0.23 *$ & $0.44^{* *}$ \\
\hline
\end{tabular}

Due to missing data, $n s$ vary as follows: age 8 family variables with age 30 alcohol variables (124-157, females; 121-159, males); age 8 personal variables with age 30 alcohol variables (196-200, females; 187-191, males); age 19 variables with age 30 alcohol variables (140-144, females; 134-135, males). ${ }^{*} P<0.05,{ }^{* *} P<0.01, \dagger P<0.10$. SES: socio-economic status.

Table 4 Correlations of age 8 and age 19 predictor variables with age 48 frequency of alcohol use and problem drinking.

\begin{tabular}{|c|c|c|c|c|}
\hline \multirow[b]{2}{*}{ Predictor variables } & \multicolumn{2}{|c|}{ Age 48 frequency of alcohol use } & \multicolumn{2}{|c|}{ Age 48 problem drinking } \\
\hline & Females & Males & Females & Males \\
\hline \multicolumn{5}{|l|}{ Age 8} \\
\hline Negative family interaction & -0.05 & 0.00 & 0.03 & 0.03 \\
\hline SES & $0.23^{* *}$ & $0.22^{* *}$ & 0.11 & 0.01 \\
\hline Behavioral inhibition & 0.11 & -0.05 & -0.01 & $-0.15^{*}$ \\
\hline Popularity & $0.14^{*}$ & 0.10 & -0.01 & -0.04 \\
\hline $\mathrm{IQ}$ & $0.12 \dagger$ & 0.09 & 0.10 & 0.06 \\
\hline Aggression & $-0.13^{*}$ & 0.02 & 0.02 & $0.13^{*}$ \\
\hline \multicolumn{5}{|l|}{ Age 19} \\
\hline Depression & 0.03 & 0.01 & 0.08 & 0.09 \\
\hline Behavioral inhibition & $-0.17^{*}$ & -0.12 & $-0.17^{*}$ & $-0.28^{* *}$ \\
\hline Popularity & $0.20^{*}$ & 0.06 & 0.13 & 0.12 \\
\hline Educational attainment & $0.16^{*}$ & 0.04 & 0.06 & $-0.16 \dagger$ \\
\hline Aggression & 0.03 & 0.09 & $0.17^{*}$ & $0.24^{* *}$ \\
\hline \multicolumn{5}{|l|}{ Age 30} \\
\hline Quantity of alcohol use & $0.48^{* *}$ & $0.40^{*}$ & $0.44^{* *}$ & $0.49^{* *}$ \\
\hline Problem drinking & $0.19^{*}$ & $0.16 \dagger$ & $0.37^{* *}$ & $0.48^{* *}$ \\
\hline
\end{tabular}

Due to missing data, $n$ s vary as follows: age 8 family variables with age 48 alcohol variables (148-186, females; 154-201, males); age 8 personal variables with age 48 alcohol variables (238-239, females; 243-244, males); age 19 variables with age 48 alcohol variables (152-153, females; 151-152, males). ${ }^{*} P<0.05,{ }^{* *} P<0.01, \dagger P<0.10$. SES: socio-economic status.

We first computed a model in which all the variables within a given wave were predicted by all variables at all previous waves, which is of course a saturated model, $\mathrm{df}=0$. This is a baseline model against which we tested subsequent models assessing whether the paths from childhood to adulthood are necessary. Then, we computed a model to assess whether the effects of the age 8 variables on the adult alcohol variables were mediated completely by the age 19 variables; no direct effects of the age 8 variables on the ages 30 or 48 alcohol variables were included. The fit statistics for this model were: $\chi^{2}=57.809$, $\mathrm{df}=48, P=0.157$, RMSEA $=0.015$. This $\chi^{2}$ statistic also represents the $\chi^{2}$ difference between this model and the saturated baseline model. Thus, the effects of the age 8 variables on the age 48 alcohol variables can be explained adequately by their mediation through the ages 19 and 30 variables. 


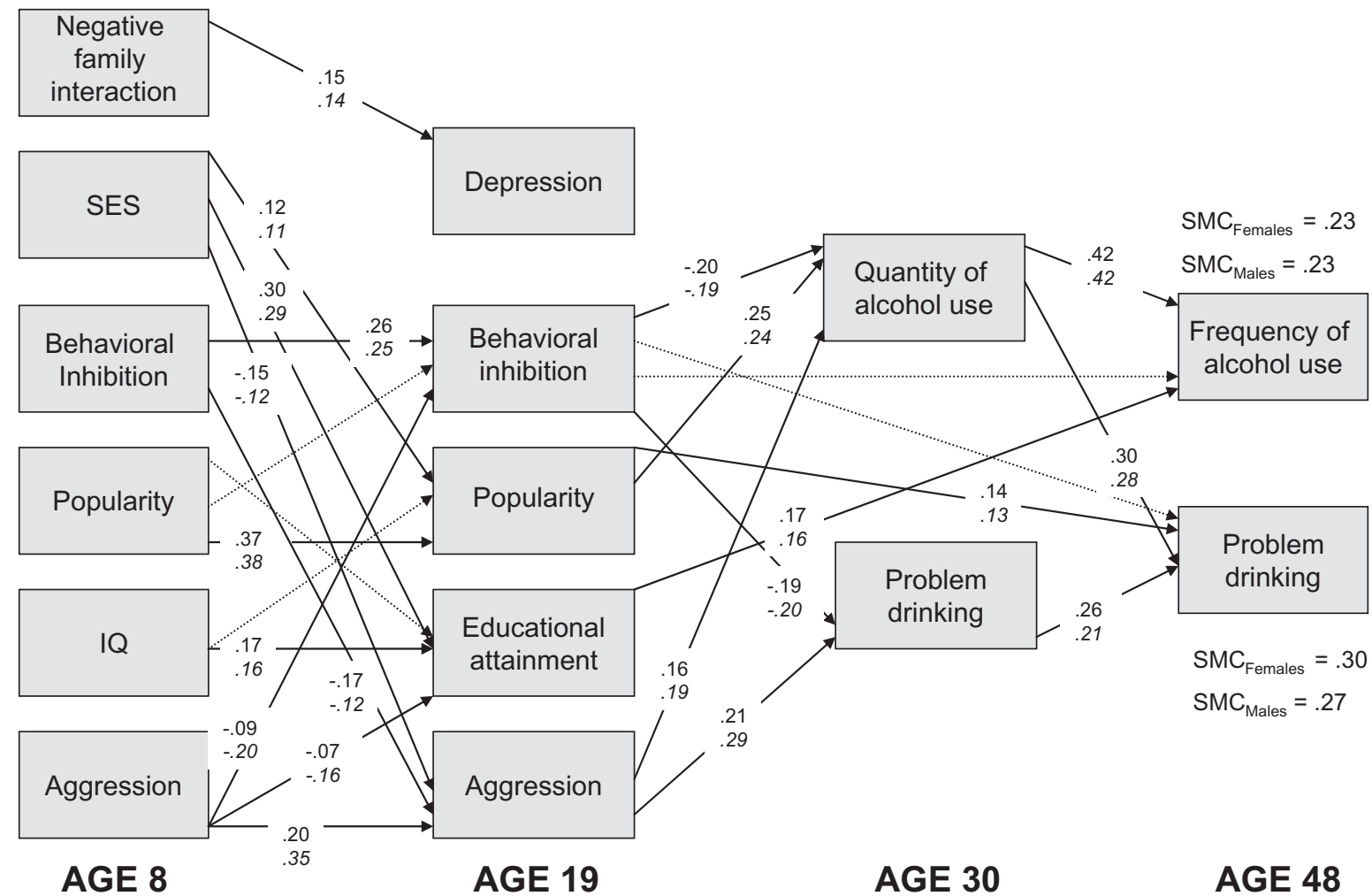

Figure I Model predicting age 48 outcomes with complete mediation of age 8 predictors to age 19 variables. All numerical values represent significant $(P<0.05)$ standardized path coefficients (coefficient for females listed on top; coefficient for males listed below in italics) for the model in which unstandardized paths were equated across gender. Non-significant paths are not shown. Dotted paths are marginally significant $(P<0.10)$. The residual terms from the predictions, the estimated correlations between these residuals, the estimated correlations between the exogenous variables and the estimated means have all been omitted for clarity of presentation. Fit statistics: $\chi^{2}=|24.791, \mathrm{df}=| 02$, $P=0.062$, RMSEA $=0.016$. SMC $=$ squared multiple correlation

Next, this model was revised by removing direct effects from the age 19 variables on the age 48 variables. This model was not a good fit for these data $\left(\chi^{2}=94.793\right.$, $\mathrm{df}=68, P=0.018$, RMSEA $=0.021)$ and fitted significantly worse compared to the previous model $\left(\chi^{2}\right.$ difference $=36.984, \mathrm{df}=20, P<0.012)$. Thus, the best-fitting model was one in which the age 19 variables mediated the relation between the age 8 variables and the adult alcohol variables.

Building on this model, we examined one further model in which we equated the path coefficients across gender. This model fitted the data acceptably $\left(\chi^{2}=124.791, \mathrm{df}=102, \quad P=0.062, \quad\right.$ RMSEA $\left.=0.016\right)$ and did not fit significantly worse than the model in which we did not equate the path coefficients across gender $\left(\chi^{2}\right.$ difference $=66.982$, df difference $=54$, $P=0.110$ ). This suggests that there is no significant difference in the path coefficients by gender; so we present this final model in which the unstandardized path coefficients are equated by gender in Fig. 1.

Figure 1 shows modest to moderate continuity in the child personal variables from ages 8 to 19. Quantity of alcohol use at age 30 was predicted by higher popularity and aggression and lower behavioral inhibition at age 19; quantity of use at age 30 predicted frequency of use and problem drinking at age 48 . Problem drinking at age 30 was predicted by lower levels of behavioral inhibition and higher levels of aggression at age 19; problem drinking at age 30 predicted more problem drinking at age 48 . There were modest direct effects of age 19 variables on age 48 frequency of use: lower behavioral inhibition and higher educational attainment predicted higher frequency of use at age 48. Lower levels of behavioral inhibition and higher levels of popularity at age 19 also predicted more problem drinking at age 48 .

\section{DISCUSSION}

We observed that childhood and adolescent risk factors were related modestly but significantly to alcohol use and abuse outcomes at ages 30 and 48 . These results are consistent with developmental research on alcohol use [1], but illustrate those effects across a longer time-span (i.e. through middle adulthood). Alcohol use and abuse are, of course, related in part to the ready availability and access to alcohol. However, alcohol use and the persis- 
tence of use also are related to enduring characteristics measurable as early as middle childhood. Childhood indicators of SES, behavioral inhibition, popularity, IQ and aggression all produced effects on subsequent indicators of functioning that ultimately accounted for variance in early and/or middle adulthood drinking and problem drinking. Our structural model predicting alcohol outcomes held across gender, indicating similar predictability of the child and adolescent factors for males and females.

Because our general framework was to examine developmental risk models for problem behavior, we began with the assertion that alcohol consumption to any degree could be one manifestation of problem behavior. Research has shown that during adolescence and early adulthood, substance use, of which alcohol use is one component, is part of a construct representing broad problem behavior that also includes aggression, antisocial behavior, academic problems and risky sexual behavior $[5,6]$. Although we did not have indicators of alcohol use measured during adolescence, correlations among our age 19 variables that are consistent with this problem behavior construct (i.e. aggression, behavioral inhibition) lend some validity to our assertion: aggression at age 19 was related positively to quantity/frequency of drinking at age 30 and to problem drinking at ages 30 and 48. Behavioral inhibition at age 19 was related negatively to quantity/frequency of drinking and problem drinking at ages 30 and 48 for males and at age 48 for females; it was related positively to quantity of drinking at age 30 for females.

Consistent with developmental studies of problem behavior construed broadly, our SEM analyses indicated that the behavioral risk factors of aggressiveness and disinhibition in childhood and adolescence led to greater quantity/frequency of drinking and problem drinking in adulthood. This is consistent with earlier studies on the development of problem drinking [16,37]. Aggression appeared to enhance the prediction of problem drinking at age 48 by also predicting quantity of drinking at age 30 , which led subsequently to increased problem drinking by age 48 . These findings also are consistent with recent findings in which the most robust predictor of alcohol use initiation was conduct disorder [2].

Interestingly, we observed that two variables traditionally viewed as protective factors in the development of problem behavior increased the likelihood of alcohol use and problem drinking. IQ (age 8) indirectly and educational attainment (age 19) directly predicted age 48 alcohol use frequency. Popularity through childhood and adolescence was linked positively to alcohol use in early adulthood, and problem drinking in middle adulthood. These effects, although paradoxical with respect to the broader risk matrix for problem behavior, are consistent with recent observations. For example, Maggs, Patrick \&
Feinstein [38] noted that alcohol can confer risks (e.g. consequences of binge drinking) as well as benefits (e.g. cardiovascular health). More education can lead to better economic standing and thus greater opportunity for social, casual drinking without necessarily increasing risk for problem drinking. Popularity (and related positively oriented individual-difference constructs such as prosocial behavior) during childhood and adolescence can be associated with elevated occupational outcomes in adulthood [25]. However, popularity also has been linked to drinking during adolescence [39], which many researchers, educators and law enforcement agencies view as a problem behavior.

Our findings contribute to the ongoing attempt to refine developmental models of alcohol use and abuse. Prospective longitudinal research on patterns of alcohol use spanning childhood and adolescence and into adulthood is relatively rare [1]. Our findings are in line with recent studies illuminating behavioral and personality factors underlying the emergence and maintenance of substance use more generally such as neurobehavioral disinhibition [40], impulsivity [41], behavioral and emotional self-control [42] and negative affectivity [43].

Our conclusions are tempered by the fact that we did not measure alcohol consumption during adolescence. Thus we cannot state conclusively that the related behavioral factors measured at age 19 'caused' or were in fact the meaningful precursors to alcohol use and abuse by age 30. Certainly, given the array of interlocking risk factors implicated in problem behavior development, alcohol consumption prior to age 19 might have accounted for difficulties at age 19 as well as subsequent alcohol use. Of course, given variability in problem drinking patterns during young adulthood [3], our age 19 variables still have meaning for understanding later problem drinking. This is underscored by the direct effects of behavioral inhibition and popularity on age 48 problem drinking even while controlling age 30 drinking. These predictors probably indicate stable personal dispositions with more enduring effects.

We note additional limitations. First, in terms of sample attrition, because the predictors of missingness were related to alcohol use and abuse outcomes at ages 30 and 48, the observed averages for frequency and problems probably underestimate the magnitude of these problems in the population. However, this underestimate should not influence the validity of the estimates we produce for the relations between these variables and their predictors given our use of SEM modeling with FIML estimation. Secondly, our measure of problem drinking focused upon negative social and legal consequences of alcohol use. We did not measure health problems or injury related to alcohol use (i.e. acute effects), which constitute much of the burden of alcohol abuse on indi- 
viduals and society [44]. Even so, those acute effects are accounted for better by specific environmental factors, such as access to alcohol or motor vehicle transport, for which we did not have indicators in our data set. On a related note, it is worth acknowledging here that our data are from a US sample; given variation in different countries in the laws and social norms governing alcohol use our findings might not generalize cross-nationally. Finally, we reiterate that problem behavior-including alcohol abuse-is a multi-determined and multi-faceted construct, and there were several issues we could not address in this investigation such as peer influence, community enforcement of alcohol laws and parental drinking habits. However, within the constraints of our investigation, we have specified and validated a longitudinal model of alcohol use and abuse that is consistent with general findings in the literature.

\section{Acknowledgements}

The authors are grateful to the National Science Foundation-supported Center for the Analysis of Pathways from Childhood to Adulthood (CAPCA) (grant no. 0322356) for research support for the analyses reported in this manuscript. We thank Sharon Simonton, CAPCA analyst, for her help with the statistical analysis of the data. The Columbia County Longitudinal Study has been supported by funding from the Columbia County Tuberculosis and Health Association and the Hudson (NY) Lions Club (1960 wave); the National Institute of Mental Health (1960, 1970 and 1981 waves); and the National Institute of Child Health and Human Development (2000 wave).

\section{Conflicts of interest}

The authors have declared no conflicts of interest.

\section{References}

1. Zucker R. A. Alcohol use and the alcohol use disorders: a developmental-biopsychosocial systems formulation covering the life course. In: Cicchetti D., Cohen D. J., editors. Developmental Psychopathology. Vol. 3. Risk, Disorder, and Adaptation, 2nd edn. New York: Wiley; 2006, p. 620-56.

2. Sartor C. E., Lynskey M. T., Heath A. C., Jacob T., True W. The role of childhood risk factors in initiation of alcohol use and progression to alcohol dependence. Addiction 2007; 102: 216-25.

3. Schulenberg J., O’Malley P. M., Bachman J. G., Wadsworth K. N., Johnston L. D. Getting drunk and growing up: trajectories of frequent binge drinking during the transition to young adulthood. J Stud Alcohol 1996; 57: 289-304.

4. Huesmann L. R., Dubow E. F., Eron L. D., Boxer P. Middle childhood family contextual and personal factors as predictors of adult outcomes. In: Huston A. C., Ripke M., editors. Developmental, Contexts of Middle Childhood. New York: Cambridge University Press; 2006, p. 62-86.
5. Ary D. V., Duncan T. E., Biglan A., Metzler C. W., Noell J. W., Smolkowski K. Development of adolescent problem behavior. J Abnorm Child Psychol 1999; 27: 141-50.

6. Jessor R., Jessor S. L. Problem Behavior and Psychosocial Development: A Longitudinal Study of Youth. New York: Academic Press; 1997.

7. DeCourville N. H. Testing the applicability of problem behavior theory to substance use in a longitudinal study. Psychol Addict Behav 1995; 9: 53-66.

8. Gottfredson M., Hirschi T. A General Theory of Crime. Palo Alto, CA: Stanford University Press; 1990.

9. Moffitt T. E. Adolescence-limited and life-course persistent antisocial behavior: a developmental taxonomy. Psychol Rev 1993; 100: 674-701.

10. Conger R. D., Patterson G. R., Ge X. It takes two to replicate: a mediational model for the impact of parents' stress on adolescent adjustment. Child Dev 1995; 66: 80-97.

11. Guerra N. G., Huesmann L. R., Spindler A. Community violence exposure, social cognition, and aggression among urban elementary-school children. Child Dev 2003; 74: 1507-22.

12. Huesmann L. R., Moise-Titus J., Podolski C. P., Eron L. D. Longitudinal relations between children's exposure to television violence and their aggressive and violent behavior in young adulthood: 1977-1992. Dev Psychol 2003; 39: 20121.

13. Scaramella L., Conger R. D., Spoth R., Simons R. L. Evaluation of a social contextual model of delinquency: a crossstudy replication. Dev Psychol 2002; 73: 175-95.

14. Warren C. W., Kann L., Small M. L., Santelli J. S., Collins J. L., Kolbe L. J. Age of initiating selected health-risk behaviors among high school students in the United States. J Adolesc Health 1997; 21: 225-31.

15. Schulenberg J. E., Maggs J. L. A developmental perspective on alcohol use and heavy drinking during adolescence and the transition to young adulthood. J Stud Alcohol 2002; 14: 54-70.

16. Chassin L., Pitts S. C., Prost J. Binge drinking trajectories from adolescence to emerging adulthood in a high-risk sample: predictors and substance abuse outcomes. J Consult Clin Psychol 2002; 70: 67-78.

17. Poikolainen K., Tuulio-Henrikkson A., Aalto-Setala T., Marttunen M., Lonnqvist J. Predictors of alcohol intake and heavy drinking in early adulthood: a 5-year follow-up of 15-19-year-old Finnish adolescents. Alcohol Alcohol 2001; 36: 85-8.

18. Wells J. E., Horwood L. J., Fergusson D. M. Drinking patterns in mid-adolescence and psychosocial outcomes in late adolescence and early adulthood. Addiction 2004; 99: 1529-41.

19. Johnston L. D., O’Malley P. M., Bachman J. G., Schulenberg J. E. Monitoring the Future National Survey Results on Drug Use, 1975-2004. Vol. I: Secondary School Students. NIH Publication no. 05-5727. Bethesda, MD: National Institute on Drug Abuse; 2005.

20. Johnston L. D., O’Malley P. M., Bachman J. G., Schulenberg J. E. Monitoring the Future National Survey Results on Drug Use, 1975-2004. Vol. II. College Students and Adults Ages 19-45. NIH Publication no. 05-5728. Bethesda, MD: National Institute on Drug Abuse; 2005.

21. Huston A. C., Ripke M., editors. Developmental, Contexts of Middle Childhood. New York: Cambridge University Press; 2006.

22. Eron L. D., Walder L. O., Lefkowitz M. M. Learning of Aggression in Children. Boston: Little, Brown; 1971. 
23. Huesmann L. R., Eron L. D., Lefkowitz M. M., Walder L. O. Stability of aggression over time and generations. Dev Psychol 1984; 20: 1120-34.

24. Lefkowitz M. M., Eron L. D., Walder L. O., Huesmann L. R. Growing Up to Be Violent: A Longitudinal Study of the Development of Aggression. New York: Pergamon Press; 1977.

25. Dubow E. F., Huesmann L. R., Boxer P., Pulkkinen L., Kokko K. Middle childhood and adolescent contextual and personal predictors of adult educational and occupational outcomes: a mediational model in two countries. Dev Psychol 2006; 42: 937-49.

26. Warner W. L., Meeker M., Eells K. Social Class in America. New York: Harcourt; 1960.

27. Jastak J. F., Jastak S. The Wide Range Achievement Test Manual of Instructions. 1978 revised edn. Wilmington, DE: Jastak Associates, Inc.; 1978.

28. Stevens G., Hoisington E. Occupational prestige and the 1980 U.S. labor force. Soc Sci Res 1987; 6: 74-105.

29. Huesmann L. R., Eron L. D. Television and the Aggressive Child: A Cross-National Comparison. Hillsdale, NJ: Erlbaum; 1986.

30. Sullivan E. T., Clark W. W., Tiegs E. W. California Short Form Test of Mental Maturity. Los Angeles: California Test Bureau; 1975.

31. Hathaway S. R., McKinley J. C. Manual for the Minnesota Multiphasic Personality Inventory. New York: Psychological Corporation; 1943.

32. Greene R. L. The MMPI: An Interpretive Manual. Orlando, FL: Grune \& Stratton; 1980.

33. Dahlstrom W. G., Welsh G. S., Dahlstrom L. E. An MMPI Handbook. Vol. II. Research Applications, revised edn. Minneapolis, MN: University of Minnesota Press; 1975.

34. Arbuckle J. L., Wothke W. Amos Users' Guide, version 4.0. Chicago: Small Waters Corporation; 1999.
35. Allison P. D. Missing Data. Thousand Oaks, CA: Sage; 2001

36. Graham J. W., Donaldson S. I. Evaluating interventions with differential attrition: the importance of nonreponse mechanisms and use of follow-up data. J Appl Psychol 1993; 78: 119-28.

37. Bennett M. E., McCrady B. S., Johnson V., Pandina R. J. Problem drinking from young adulthood to adulthood. Patterns, predictors, and outcomes. J Stud Alcohol 1999; 60: 605-15.

38. Maggs J., Patrick M., Feinstein L. Childhood and adolescent predictors of alcohol use and problems in adolescence and adulthood in the National Child Development Study. Addiction 2008; 103 (Suppl. 1): 7-22.

39. Diego M. A., Field T. M., Sanders C. E. Academic performance, popularity, and depression predict adolescent substance use. Adolescence 2003; 38: 35-42.

40. Kirisci L., Vanyukov M., Tarter R. Detection of youth at high risk for substance use disorders: a longitudinal study. Psychol Addict Behav 2005; 19: 243-52.

41. Barnes G. M., Welte J. W., Hoffman J. H., Dintcheff B. A. Shared predictors of youthful gambling, substance use, and delinquency. Psychol Addict Behav 2005; 19: 165-74.

42. Wills T. A., Walker C., Mendoza D., Ainette M. G. Behavioral and emotional self-control: relations to substance use in samples of middle and high school students. Psychol Addict Behav 2005; 20: 265-78.

43. Measelle J. R., Stice E., Springer D. W. A prospective test of the negative affect model of substance abuse: moderating effects of social support. Psychol Addict Behav 2006; 20: 225-33.

44. Rehm J. R., Room R., Monteiro M., Gmel G., Graham K., Rehn N. et al. Alcohol as a risk factor for global burden of disease. Eur Addict Res 2003; 9: 157-64. 